\title{
Inundation mapping of Kerala flood event in 2018 using ALOS-2 and temporal Sentinel-1 SAR images
}

\author{
V. S. K. Vanama ${ }^{1, *}$, Mohamed Musthafa ${ }^{2}$, Unmesh Khati ${ }^{2}$, R. Gowtham ${ }^{2}$, \\ Gulab Singh ${ }^{2}$ and Y. S. Rao $^{2}$ \\ ${ }^{1}$ Centre for Urban Science and Engineering, and \\ ${ }^{2}$ Centre of Studies in Resources Engineering, Indian Institute of Technology Bombay, Mumbai 400 076, India
}

\begin{abstract}
In August 2018, the southern Indian state of Kerala received unusually heavy rainfall leading to largescale flooding and destruction. Reliable flood inundation maps derived from remote sensing techniques help in flood disaster management activities. The freely available Sentinel-1A/B SAR data have the potential for flood inundation mapping due to its all-weather imaging capability. In this study, temporal dual-pol Sentinel-1 SAR data have been utilized. Single-date ALOS-2/PALSAR-2 commercial SAR data were also used to fill the gap between Sentinel-1 acquisitions during the peak flood-period. Two flood-mapping approaches, viz. rule-based classification in case of temporal SAR data and histogram-based thresholding approach in case of single-date imagery, were utilized in the study. Also, flood inundation mapping with different data constraints, i.e. availability of single-date and multi-date imagery has been analysed and discussed. The obtained results were validated with multiple data sources like survey data and secondary data from government agencies. An overall accuracy of $90.6 \%$ and a critical success index of $81.6 \%$ were achieved with the proposed rule-based classification approach. This study highlights the potential of the combination of Sentinel-1 and ALOS-2/PALSAR-2 data for flood inundation mapping.
\end{abstract}

Keywords: Disaster management, floods, inundation mapping, remote sensing, rule-based classification.

FLOODS usually inundate a dry land area and can result in substantial socio-economic losses due to their impact on transport and utility networks ${ }^{1}$. Flood events require constant monitoring and mapping for effective and timely management of rescue and relief operations. Recent floods in the southern Indian state of Kerala have inundated large parts of the coastal area as well as many urban and agricultural regions. Monitoring floods on a large scale using in-situ observations is limited by their geographic extent and the terrain. Remote sensing techniques

*For correspondence. (e-mail: vsaikrishna1990@gmail.com) have been successfully utilized for flood monitoring, hazard mapping $^{2}$, risk assessment ${ }^{3,4}$ as well as modelling, and validation of weather forecasting and rainfall-runoff models. Optical remote sensing techniques have been successfully utilized for inundated region mapping exploiting the different spectral responses and using various image classification techniques ${ }^{5}$. However, these techniques are limited by cloud cover, especially over the tropics.

Synthetic Aperture Radar (SAR) techniques have allweather sensing capability and penetrate clouds, providing complementary active remote sensing data crucial for the tropical regions. Microwave signal backscatter is sensitive to changes in the target dielectric properties and structure, which provides a fundamentally different response from the water-covered areas. This provides a distinct ability to accurately estimate the waterbody extent using SAR data. The SAR data have been utilized for boundary mapping of water bodies ${ }^{6,7}$, being sensitive to tidal fluctuations. The combined use of optical and SAR data is also exploited for inundation mapping ${ }^{8,9}$. A review of SAR-based flood detection methods under forest canopy was done by Hess et al. ${ }^{10}$. Multi-frequency and multipolarization data have been used in various studies ${ }^{1-14}$. Many studies have demonstrated the capabilities of Advanced Land Observing Satellite Phased Array L-band Synthetic Aperture Radar (ALOS/PALSAR and ALOS2/PALSAR-2) images in flood extent mapping of different land uses ${ }^{15,16}$. The combined use of ALOS PALSAR with other satellite data such as Radarsat-2 (ref. 17), Cosmos Skymed ${ }^{18-20}$ and TerraSAR- $\mathrm{X}^{21}$ has also been explored to compare the inundation mapping results obtained from different wavelengths. Sentinel-1 images are useful to monitor the flood events in near real-time at a larger spatial region using the target region search method $^{22}$. The combined use of AWiFS optical images and Sentinel-1 SAR images was explored in riverinebased flood monitoring ${ }^{23}$.

A thresholding algorithm combined with Digital Elevation Model (DEM) was used to identify flooded areas from Radarsat-1 SAR imagery ${ }^{24}$. A supervised decision tree classifier was used for wetland mapping using 


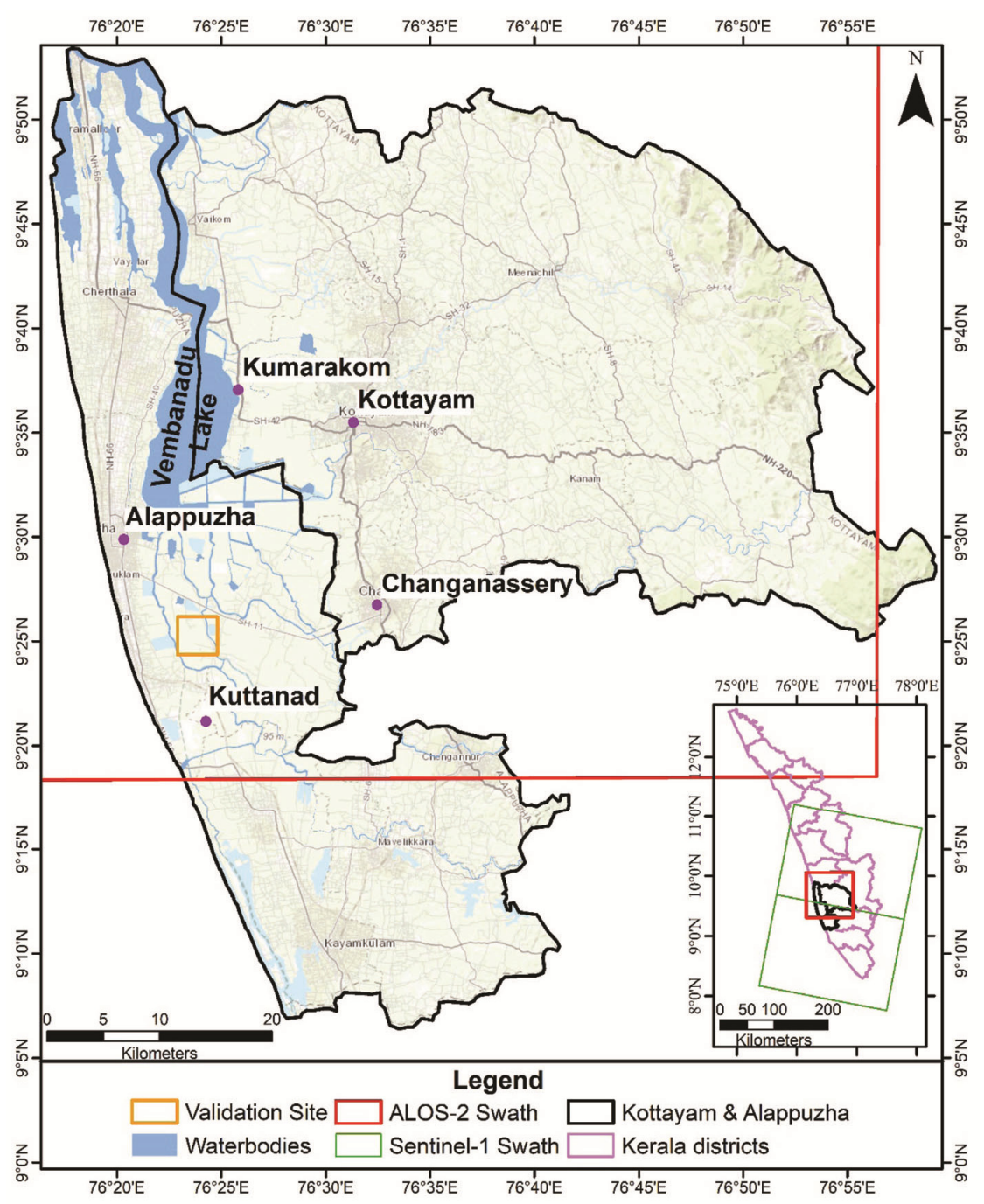

Figure 1. Study area showing Alappuzha and Kottayam districts in Kerala, India.

C-band CCRS airborne SAR data by Baghdadi et al. ${ }^{25}$. Split-based automatic thresholding was developed by Greifeneder et al. $^{26}$ using 696 ENVISAT ASAR archived images for waterbody mapping. Split window approach has also been used for flood damage assessment ${ }^{27}$. A hierarchical split-based approach combined with region growing and change detection was demonstrated for flood mapping with an overall accuracy of $89 \%$ (ref. 28). An automated approach combining backscatter-optimized thresholding, region growing and change detection was proposed for flood mapping in urban areas ${ }^{29}$. Interferometric coherence was also used for detecting flooded urban and vegetation areas ${ }^{30,31}$.

The launch of Sentinel-1A/B satellites by European Space Agency (ESA) provides the first freely available SAR data acquired in dual-polarization mode with a temporal resolution of 12 days. Inundation mapping with the Sentinel-1 ground range detected (GRD) products using cloud processing with Google Earth Engine was done by Amitrano et al. $^{32}$. Few studies describe multi-temporal
Sentinel-1 data capabilities for inundation mapping in different land uses/land covers ${ }^{33-35}$. The combined use of ALOS-2 and Sentinel-1 in the delineation of flooded vegetation was explored by Plank et al. ${ }^{36}$. A multitemporal colour composite flood area delineation was also proposed using dual-pol Sentinel-1 data in conjunction with $\mathrm{DEM}^{34}$.

In this study, a simple and robust rule-based algorithm has been developed using Sentinel-1 SAR data for mapping flood inundation. The results obtained were validated with a ground-based survey and also with secondary data from Government agencies.

\section{Study area and datasets}

Two districts in Kerala, viz. Kottayam and Alappuzha, which were among the eight districts that experienced devastating flood events during August 2018, were studied in detail (Figure 1). 

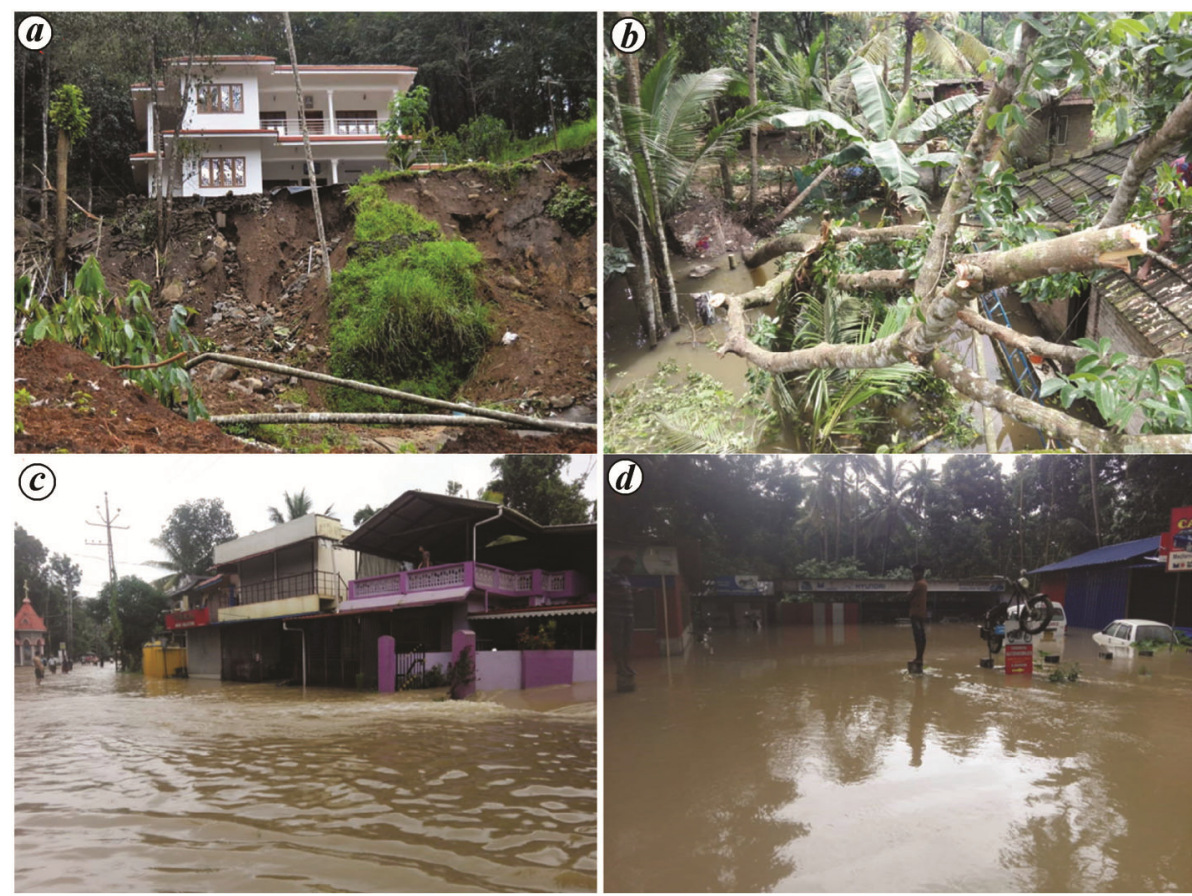

Figure 2. Photographs captured on 9 September 2018 show the devastation caused by the floods in (a) Padanad, (b) Chengannur, (c) Kadapra and $(\boldsymbol{d})$ Thiruvalla towns in Alappuzha district, Kerala (photos credit: Harsha Rajan).

Table 1. SAR data utilized in mapping flood inundation

\begin{tabular}{lccccc}
\hline DoA & Satellite & $\begin{array}{c}\text { Acquisition } \\
\text { mode }\end{array}$ & Polarization & $\begin{array}{c}\text { Incidence } \\
\text { angle }\end{array}$ & $\begin{array}{c}24 \text { h rainfall } \\
(\mathrm{mm})\end{array}$ \\
\hline 5 May 2018 & Sentinel-1 & IWS & VV + VH & 38.615 & - \\
22 June 2018 & Sentinel-1 & IWS & VV + VH & 38.615 & 28.9 \\
16 July 2018 & Sentinel-1 & IWS & VV + VH & 38.615 & 128 \\
28 July 2018 & Sentinel-1 & IWS & VV + VH & 38.615 & 2.11 \\
9 August 2018 & Sentinel-1 & IWS & VV + VH & 38.615 & 24.77 \\
21 August 2018 & Sentinel-1 & IWS & VV + VH & 38.615 & 4.63 \\
17 August 2018 & ALOS-2 & Stripmap & HH + HV & 36.283 & 78.45 \\
23 February 2018 & Sentinel-2 & M1LC & B8/B4/B3 & - & \\
\hline
\end{tabular}

DoA, Date of acquisition; IWS, Interferometric wide swath.

The study area was selected since it is characterized by multiple landuses such as urban, rural and also ecologically sensitive land features such as wetlands and mangroves. The Vembanad lake, a Ramsar site ${ }^{37}$, is also present in the study region. It is considered to be the largest brackish-water lake in India. The Vembanad lake is fed mainly from 10 different rivers and rivulets, of which major rivers that directly drain into it are Pamba, Achenkovil, Manimala and Meenachil; a part of the Periyar also drains near Cochin, which eventually reaches the Arabian Sea. Due to perennial water availability, many fish-farms and paddy fields were developed at the periphery of the lake area. Torrential rainfall in several parts of Kerala resulting from the southwest monsoon and continuous heavy rainfall during August 2018 resulted in significant accumulation of rainwater in many dams. Heavy rainfall, along with the controlled release of dam water, caused sudden flood-like conditions in the state. The floods resulted in massive-scale damage to urban and rural regions. Figure 2 shows the extent of damage visible after the rainfall subsided by the end of August 2018.

\section{Data}

In this study, temporal level-1 GRD Sentinel-1 C-band SAR images with VV/VH polarization and a Single Look Complex (SLC) ALOS-2 SAR image with HH/HV polarization were utilized. Table 1 provides details of SAR data characteristics and the date of acquisition. The average $24 \mathrm{~h}$ precipitation obtained from the India Meteorological Department (IMD) station at Kottayam is also shown in the table ${ }^{38}$. 


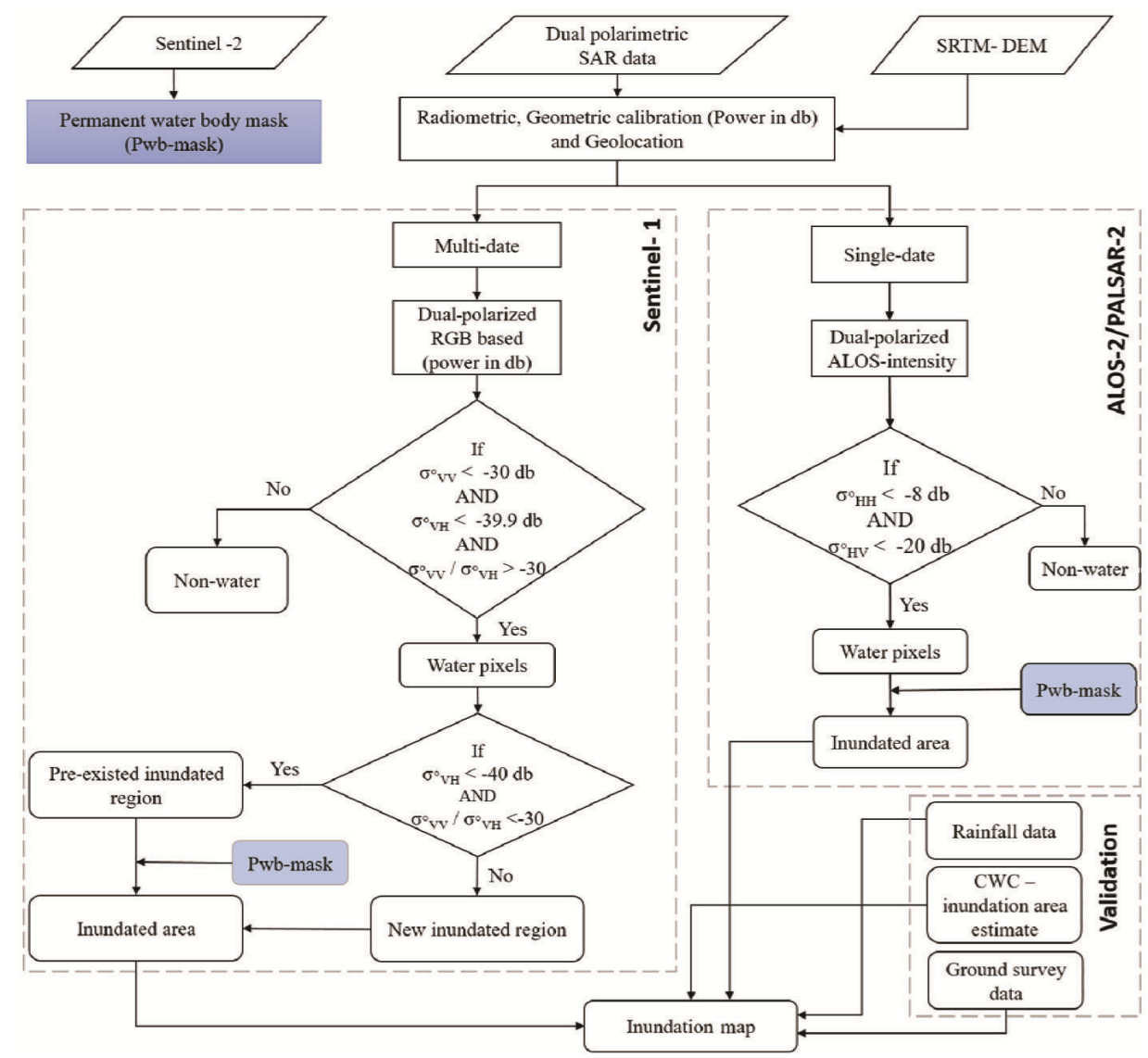

Figure 3. Rule-based classification algorithm for single date and multi-date SAR data in inundation mapping. The single-date inundation analysis was done using $L$-band ALOS-2/PALSAR-2, while the multi-date inundation analysis was performed on Sentinel-1 time-series data.

There was a major rainfall event between 15 August and 17 August 2018, where the rainfall measured in Kottayam for these three days was 99,79 and $79 \mathrm{~mm}$ respectively $^{38}$. This massive surge in rainfall in mid-August caused fresh inundation of large tracts of the study region.

\section{Methodology}

\section{SAR data pre-processing}

The GRD Sentinel-1 data were calibrated using the SNAP toolbox to convert pixel intensity into radar backscatter coefficient. The obtained radar backscatter images were multi-looked with three looks in the azimuth and three looks in the range direction, which resulted in $30 \mathrm{~m}$ pixel size. Multi-looked radar backscatter images were then geocoded using the range-Doppler terrain correction algorithm in the SNAP toolbox. The level 1.1 SLC ALOS-2/PALSAR-2 data were pre-processed using SNAP software. The SLC data were calibrated to form a radar backscatter $\left(\sigma^{0}\right)$ product and further multi-looked with four looks in the azimuth and seven looks in the range direction, which resulted in $28 \mathrm{~m}$ pixel resolution.
The calibrated multi-looked imagery was geocoded using 1 arc sec SRTM DEM.

\section{Selection of training dataset}

Sentinel-2 optical false colour composite (FCC) imagery was used for manual digitization of test samples in the experiment. Test polygons were selected from the image for permanent water areas, urban regions and other land uses, and they were categorized as water, urban and other classes. The chosen test polygons were overlaid on the SAR imagery for further analysis. The permanent waterinundated region sample comprises $1.56 \mathrm{sq} . \mathrm{km}$ (1727 pixels), while the urban class sample contains $1.44 \mathrm{sq} . \mathrm{km}$ (1600 pixels), and all other features were combined under other classes having an area of $4.03 \mathrm{sq}$. km (4485 pixels). The third class defined as 'other classes', comprises mostly rural areas with human settlements and vegetation.

\section{Flood detection approaches}

In this study, the potential of single-date and multi-date SAR imagery having dual-polarization (VV/VH or $\mathrm{HH} / \mathrm{HV}$ ) 
in flood detection and quantification is demonstrated. Sentinel-1 SAR data were used in multi-date flood detection and inundation mapping approach, while ALOS-2/ PALSAR-2 imagery was used in single-date flood detection and inundation mapping. The methods used in this study are categorized based on either single-date or multidate images described hereafter. Figure 3 summarizes the methodology implemented for this study in the flowchart.

Multi-date dual-pol Sentinel-1-derived inundation mapping: A rule-based classifier was developed using dualpolarization SAR data to differentiate permanent water bodies, flooded/inundated areas and non-water regions from a stack generated from pre-flood and post-flood images. An RGB image was generated based on the flood water inundation mapping by Jo et $a l .{ }^{34}$. The calibrated images were converted into decibel scale using the formula $20 \log _{10}(\mathrm{DN})$, where the DN refers to the calibrated linear radar backscatter power values. $\sigma_{\mathrm{VV} \text {-post }}^{0}$ was assigned to the red band, $\sigma_{\mathrm{VH}-p o s t}^{0}$ to the green band, and $0.5 *\left(\sigma_{\mathrm{VV}-\text { pre }}^{0}+\sigma_{\mathrm{VH}-\mathrm{pre}}^{0}\right)$ assigned to the blue band. It has been demonstrated that pre-existing water exhibits black colour, whereas flooded water shows a blue colour, and the rest of the features such as vegetation and urban exhibit red to green colour shades ${ }^{34}$. Sentinel-1 image acquired on 5 May 2018 was considered pre-flood, whereas the imagery acquired during August 2018 at which the flood event occurred was considered as post-flood imagery. Since the blue-coloured region depicts flooded area, a simple logical rule was developed to segregate only blue colour from the imagery, thereby extracting only the flooded region. The unique feature of this technique is the non-requirement of existing water body GIS layers to extract flooded regions. Figure 3 describes the rule-based classifier. The regions classified as pre-inundated and newly inundated were combined and permanent water bodies were masked, and the resultant water pixels were used to estimate the total inundation area. However, using this approach, flooding in urban areas might be slightly underestimated due to shadows and double/multiple bounce scattering from the built structures.

Single-date ALOS-2/PALSAR-2-derived inundation mapping: The calibrated ALOS-2/PALSAR-2 data acquired on 17 August 2018 was the only available seen between 9 and 21 August 2018, during which the rainfall and flood inundation were maximum. From the ALOS-2 SAR backscatter, a few samples were selected from water and non-water classes, and their statistical mean and standard deviation parameters were computed for $\sigma_{\mathrm{HH}}^{0}, \sigma_{\mathrm{HV}}^{0}$ and $\sigma_{\mathrm{HH}}^{0} / \sigma_{\mathrm{HV}}^{0}$ (Table 2).

Based on the above statistical analysis, a threshold of $-8 \mathrm{~dB}$ in $\mathrm{HH}$ polarization and $-20 \mathrm{~dB}$ in $\mathrm{HV}$ polarization was chosen, and pixels less than both the threshold values were assigned as water pixels and the rest as a non-water feature. The classified binary output was subjected to morphological operations to fill the gaps. The permanent water body was masked to obtain a more reliable flood inundated area.

\section{Accuracy assessment approach}

As the flood event occurred at a larger spatial scale, i.e. at many locations in Kerala, it is difficult to validate a larger region due to resource constraints. So, a small site, as shown in Figure 1, which was heavily affected by the flood, was chosen for accuracy assessment. The validation data were collected in the third week of August 2018 after the heavy rainfall. Hence, the result obtained from the SAR image acquired on 21 August 2018 was utilized in the accuracy assessment. Validation points were collected from the flood-affected area, and the information was used for digitizing flood-area polygons manually. The polygon vector was rasterized with the same spatial resolution of the SAR image with flood and non-flood classes. Different performance indices exist to assess the flood mapping accuracy, such as overall accuracy ${ }^{33}$, probability of detection (POD), false alarm rate (FAR) ${ }^{39}$ and consistent rate ${ }^{40}$. Many of these performance indices are derived based on the number of pixels detected as flood/non-flood by the algorithm and ground truth data (Table 3).

Producer's (PA), user's (UA) and overall (OA) accuracies are the widely used measures for either a multi-class or binary class categorization problem. The accuracies of non-flood and flood classes are derived as follows

$$
\begin{aligned}
& \mathrm{PA}_{\mathrm{f}}=\frac{A}{A+C}, \mathrm{PA}_{\mathrm{nf}}=\frac{D}{B+D}, \\
& \mathrm{UA}_{\mathrm{f}}=\frac{A}{A+B}, \mathrm{UA}_{\mathrm{nf}}=\frac{D}{C+D}, \\
& \mathrm{OA}=\frac{A+D}{A+B+C+D}, \mathrm{CSI}=\frac{A}{A+B+C},
\end{aligned}
$$

Table 2. Statistical analysis of ALOS-2/PALSAR-2 SAR backscatter

\begin{tabular}{lrccc}
\hline & \multicolumn{2}{c}{$\sigma_{\mathrm{HH}}^{0}$} & \multicolumn{2}{c}{$\sigma_{\mathrm{HV}}^{0}$} \\
\cline { 2 - 5 } Parameters & Water & Non-water & Water & Non-water \\
\hline Mean & -18.26 & -2.74 & -30.9 & -10.87 \\
Standard deviation & 2.08 & 3.99 & 1.52 & 3.15 \\
\hline
\end{tabular}

Table 3. Flood mapping performance metrics

\begin{tabular}{lccc}
\hline & & \multicolumn{2}{c}{ Validation data } \\
\cline { 3 - 4 } & & Flood & Non-flood \\
\hline Rule-based output & Flood & $4920(\mathrm{~A})$ & $1010(\mathrm{C})$ \\
& Non-flood & $10113(\mathrm{~B})$ & $58435(\mathrm{D})$ \\
\hline
\end{tabular}



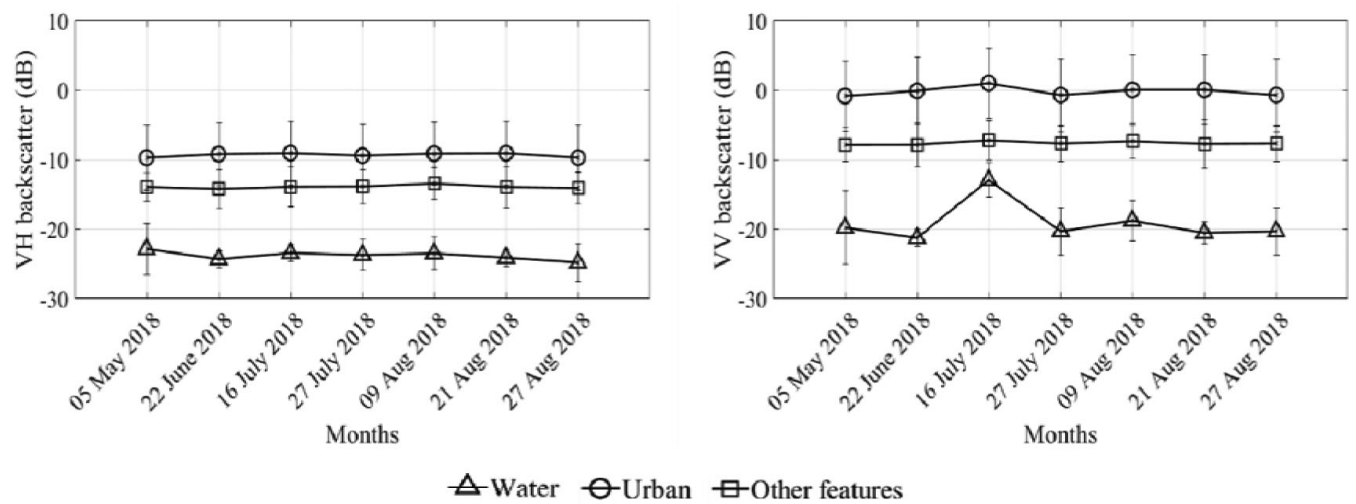

Figure 4. Trend showing VV and VH polarization mean backscatter and standard deviation for waterbodies, urban areas and other features.
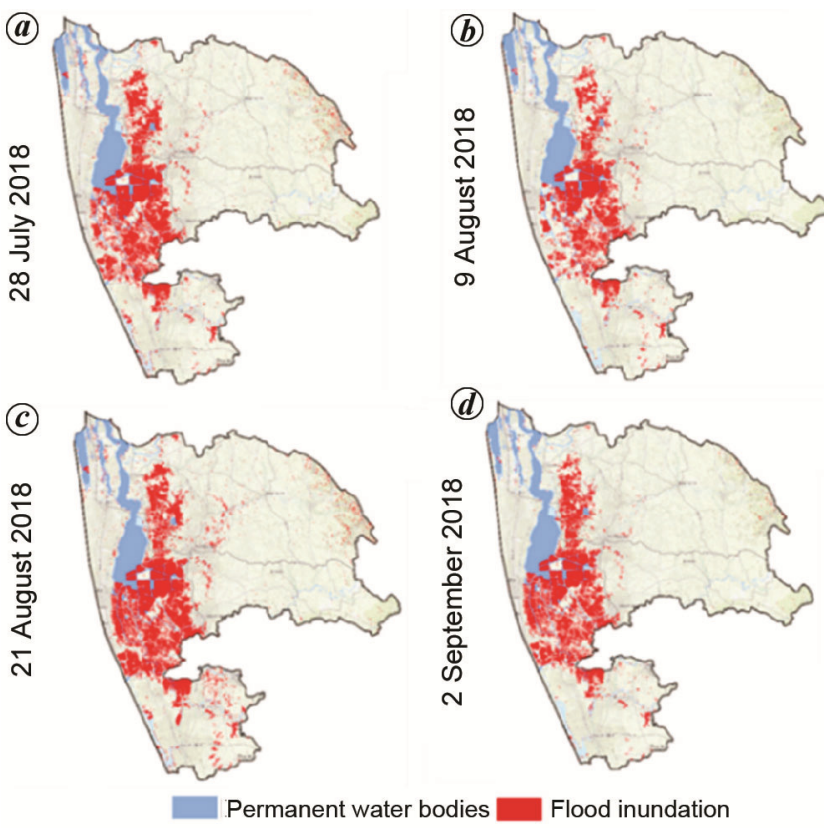

Figure 5. Time-series Sentinel-1-based inundation mapping. (a-d) Inundation maps derived using dual polarization Sentinel-1 SAR data.

$$
\text { Kappa } \left.(\kappa)=\frac{(A+D)-\left(\frac{\left[\begin{array}{c}
(((A+B) *(A+C))+ \\
((C+D) *(B+D)))
\end{array}\right]}{(A+B+C+D)}\right)}{(A+B+C+D)-\left(\begin{array}{c}
(((A+B) *(A+C))+ \\
((C+D) *(B+D)))
\end{array}\right]}\right),
$$

where $f$ and $n f$ in eq. (1) denote flood and non-flood class. High $\mathrm{PA}_{\mathrm{f}}$ denotes low overestimation and vice versa, and the same rationale holds for $\mathrm{UA}_{\mathrm{f}}$. However, in the flood mapping approach, the non-flood class is quantitatively larger than the flood class ${ }^{6,41}$. This would result in overall accuracy overestimation due to its sensitivity to the size of the non-flood class. Whereas $\mathrm{CSI}^{42}$ does not consider truly classified non-flood pixels to be reliable in the flood mapping accuracy assessment approach. Also, Cohen's kappa coefficient $(\kappa)$ is derived for measuring the reliability between ground truth and algorithm output ${ }^{43,44}$. In this study, we have derived all the above-mentioned indices.

\section{Results}

The radar backscatter trend for different land features was analysed, and the results of water inundation mapping by single-date and multi-date-based SAR techniques have been demonstrated. Test polygons were selected from the image for permanent water areas, urban regions and other land-use features. The test polygons were categorized as water, urban and other classes for statistical analysis (Figure 4).

Due to the strong double-bounce effect from an urban area, a relatively high backscatter was observed in co-pol (VV) than cross-pol (VH). Whereas due to specular reflection from water bodies very low backscatter was observed in both VV and VH polarizations. In VV polarization, the backscatter values for urban and water classes ranged from -0.9 to $0 \mathrm{~dB}$ and -21 to $-18 \mathrm{~dB}$ respectively. In $\mathrm{VH}$ polarization, it varied from -9.8 to $-9 \mathrm{~dB}$ and -24 to $-22 \mathrm{~dB}$ respectively.

\section{Multi-date Sentinel-1-based flood inundation mapping}

Sentinel-1 dual-pol (VV/VH) data were used in inundation mapping by applying the rule-based algorithm and time-series inundation maps were generated. Though the water pixels were further delineated into the pre-existing inundated area and freshly inundated area, both the water classes were combined to estimate the total floodinundated area. The pre-existing inundated area does not include permanent water bodies because the Sentinel-1 GRD product has an in-built water mask, eliminating the permanent water bodies. Hence in this study the permanent water bodies were masked in order to estimate the flood-inundated area. Figure 5 shows the inundated area before, during and after the floods. The red colour depicts 
the inundated region, and the blue colour shows permanent water bodies.

\section{Single-date ALOS-2/PALSAR-2 flood inundation mapping}

From the single ALOS-2/PALSAR-2 SAR data, the radar backscatter values of $\sigma_{\mathrm{HH}}^{0}$ and $\sigma_{\mathrm{HV}}^{0}$ were used to delineate water and non-water pixels. Based on the backscatter analysis of test polygons on ALOS-2/PALSAR-2 backscatter imagery, a simple rule-based classifier was developed to delineate water and non-water pixels. In this single-date flood inundation map, the results obtained do not cover the entire study area (Figure 6).

The flood event occurred following excess rainfall event from 15 to 17 August 2018 (Table 1). No Sentinel1 imagery was available immediately during the flood event, which resulted in a gap in the flood inundation analysis. The single ALOS-2/PALSAR-2 dual-polarization data acquired on 17 August 2018 were used to fill the gap in flood inundation mapping of the Sentinel-1 time series. As discussed earlier, the ALOS-2 swath does not cover the entire study area; the results obtained were clipped to the ALOS-2 swath extent. To maintain consistency, the spatial extent of ALOS-2 results were confined to the same spatial extent of Sentinel-1 for further analysis.

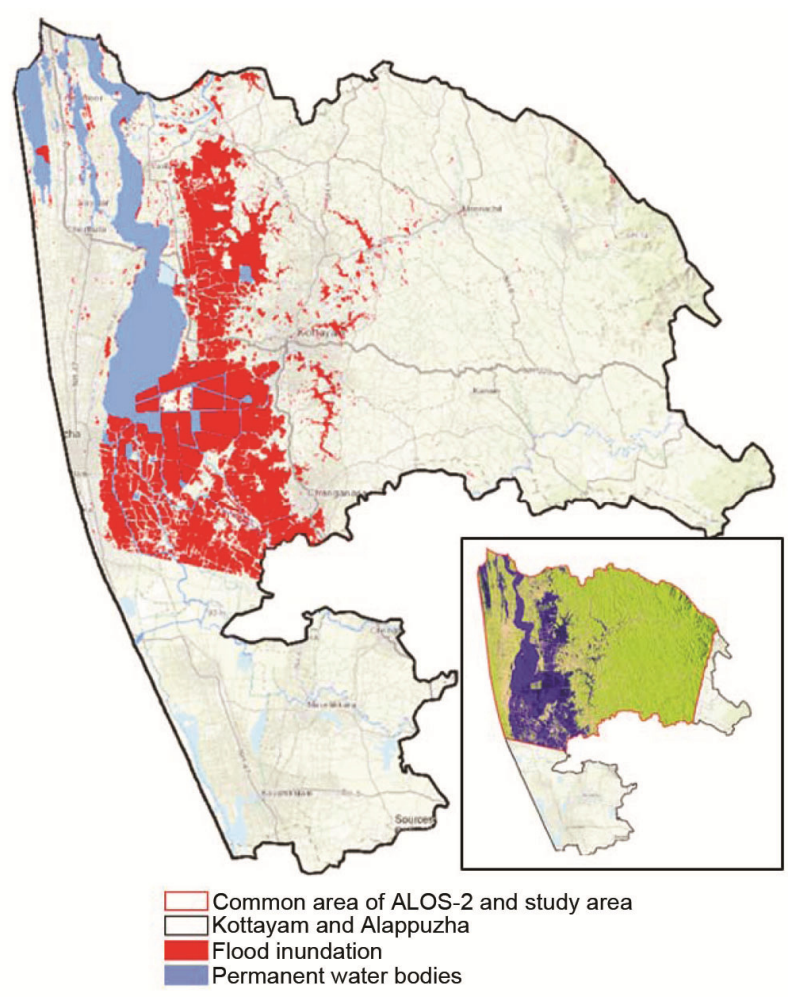

Figure 6. Flood inundation region shown in red colour mapped using single-date dual-pol ALOS-2/PALSAR-2 data on 17 August 2018 (Inset) RGB composite of ALOS-2/PALSAR-2 image with red band assigned to $\mathrm{HH}$ polarization, green band to $\mathrm{HV}$ polarization and $\mathrm{HH} / \mathrm{HH}$ ratio assigned to blue band.
Table 4 gives the change in inundated regions for the gap-filled time series. The table also clearly shows the increase in inundated regions following heavy rainfall between 15 and 17 August 2018. The increase in the inundated area during July was due to the rainfall event on 16 July 2018 (ref. 38).

\section{Accuracy assessment}

The accuracy assessment was performed as described earlier. The permanent water body pixels were excluded while calculating the indices. $\mathrm{UA}_{\mathrm{f}}$ and $\mathrm{UA}_{\mathrm{nf}}$ values were $97.9 \%$ and $85.2 \%$ respectively, indicating that the flood area generated by the RGB method matches with ground truth data (Table 5). The OA, CSI and $\kappa$ values were $90.6 \%, 81.6 \%$ and $81.2 \%$ respectively, indicating a close match to the reference data.

\section{Discussion}

Multiple torrential rainfall events in Kerala have caused sudden flood events in eight out of 14 districts of the state. In this study two districts were chosen and the inundation area was mapped before and after the flood event. The study area is peculiar since it has perennial inundated regions due to either the spill from Vembanad lake or agricultural activities. This study analysed the potential of Sentinel-1 dual-pol temporal data to map and differentiate permanently inundated and freshly inundated areas. The flood inundation mapped using L-band ALOS2/PALSAR-2 dual-pol data was used to fill the gap between 9 and 21 August when the flood was at its peak.

Table 4. Flood inundation area estimated by different SAR-based techniques (analysis done for ALOS-2/Sentinel-1 common area covering part of the study area only)

\begin{tabular}{lcc}
\hline & \multicolumn{2}{c}{ Inundation area (sq. km) } \\
\cline { 2 - 3 } Parameters & Dual-pol Sentinel-1 & ALOS-2/PALSAR-2 \\
\hline 22 June 2018 & 304.6 & - \\
16 July 2018 & 326.41 & - \\
28 July 2018 & 303.63 & - \\
9 August 2018 & 246.47 & - \\
17 August 2018 & - & 363.82 \\
21 August 2018 & 336.48 & - \\
27 August 2018 & 336.09 & - \\
2 September 2018 & 284.34 & - \\
\hline
\end{tabular}

Table 5. Performance metrics for the validation site

\begin{tabular}{lc}
\hline & Rule-based method (\%) \\
\hline Producer accuracy - flood class $\left(\mathrm{PA}_{\mathrm{f}}\right)$ & 82.90 \\
Producer accuracy - non-flood class $\left(\mathrm{PA}_{\mathrm{nf}}\right)$ & 98.30 \\
User accuracy - flood class $\left(\mathrm{UA}_{\mathrm{f}}\right)$ & 97.90 \\
User accuracy - non-flood class $\left(\mathrm{UA}_{\mathrm{nf}}\right)$ & 85.20 \\
Overall accuracy $(\mathrm{OA})$ & 90.60 \\
Critical success index $(\mathrm{CSI})$ & 81.60 \\
Kappa coefficient & 81.27 \\
\hline
\end{tabular}




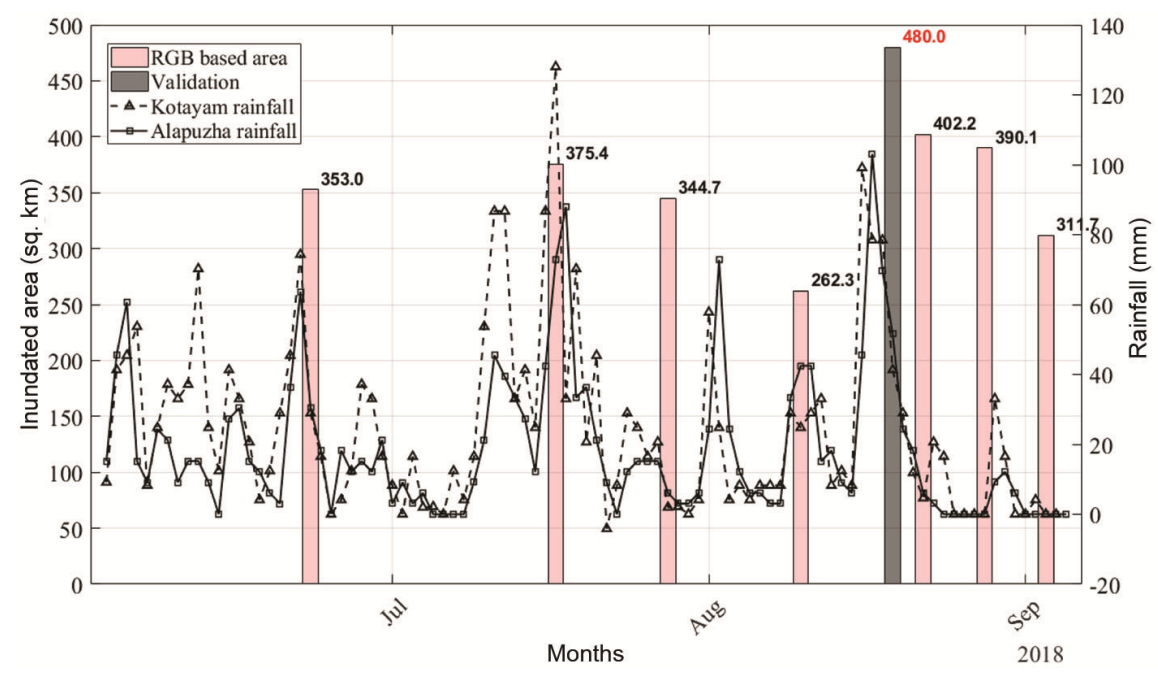

Figure 7. Graph showing inundated area estimated by RGB-based method. The light pink colour depicts RGB-based estimate and grey-coloured bar shows the validation data of the Central Water Commission (2018). Line plots show rainfall data for Kottayam and Alappuzha districts, Kerala.

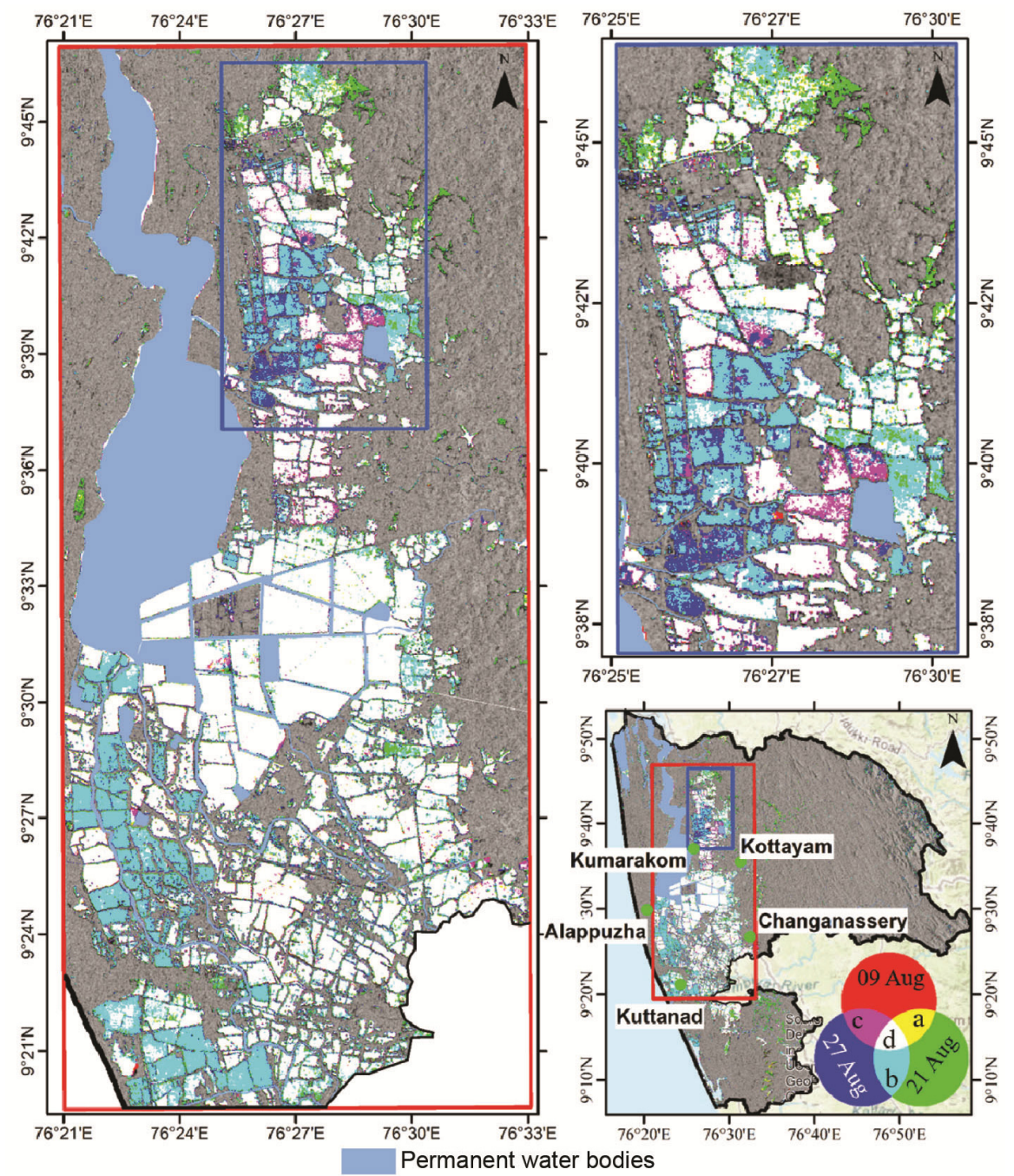

Figure 8. Change map showing the occurrence of flood inundation using RGB composite from dual-pol based inundation maps. Red band is assigned to 9 August, green band to 21 August and blue band to 27 August 2018 . 


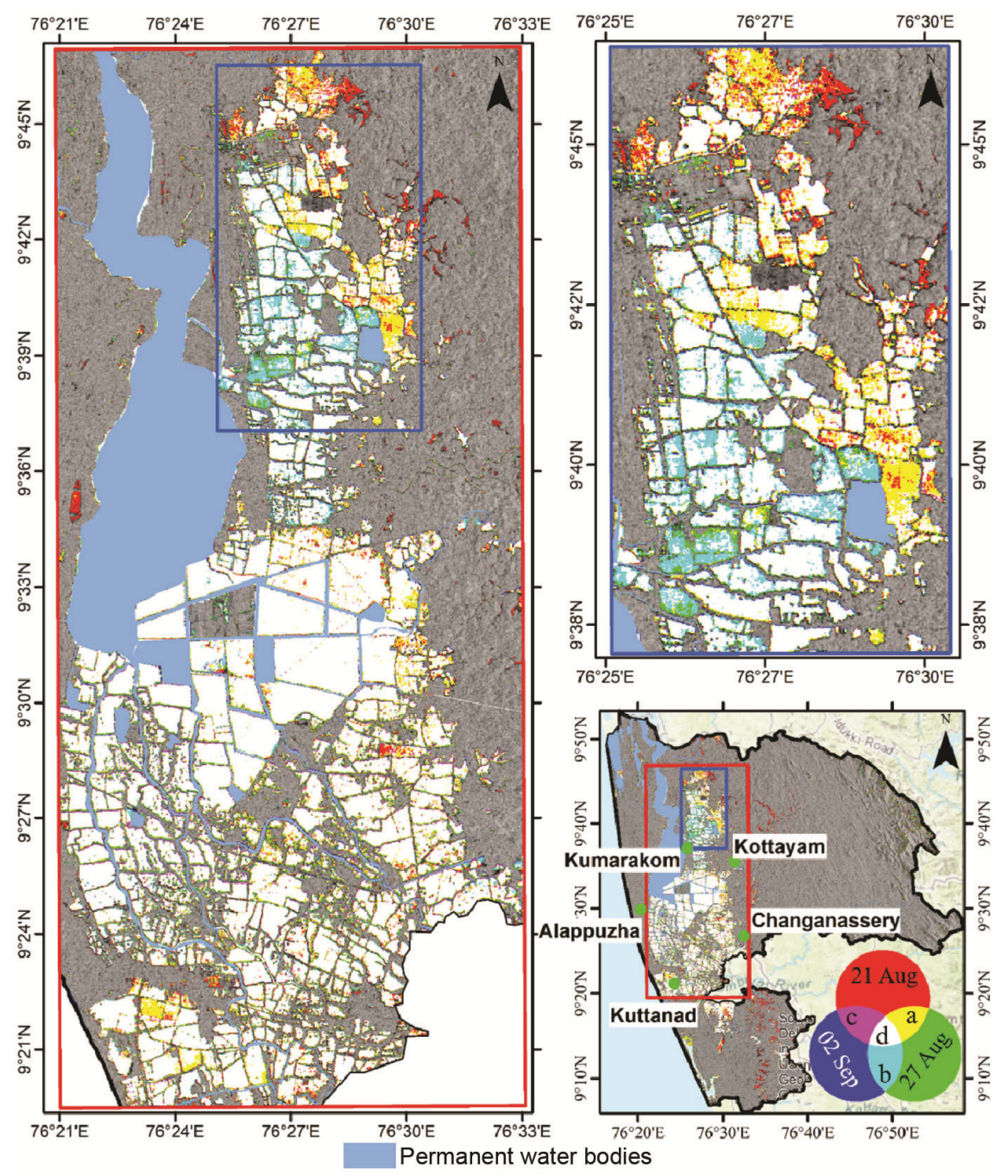

Figure 9. Change map showing recession of flood inundation using RGB composite from dual-pol based inundation maps. Red band is assigned to 21 August, green band to 27 August and blue band to 2 September 2018 .

Table 6. Occurrence and recession of flood - RGB composite inputs

\begin{tabular}{lll}
\hline Band & Change map 1 & \multicolumn{1}{c}{ Change map 2 } \\
\hline Red & 9 August 2018 & 21 August 18 \\
Green & 21 August 18 & 27 August 18 \\
Blue & 27 August 2018 & 2 September 2018 \\
\hline
\end{tabular}

Figure 7 shows the change in the inundated area estimated by the techniques and the rainfall data ${ }^{38}$ of the total study area.

The inundation area increased swiftly after the increase in rainfall on 16 July and 21 August 2018. On 16 July 2018 , there was torrential rainfall in Kottayam (more than $450 \mathrm{~mm}$ ) whereas Alappuzha had comparatively less rainfall $(290 \mathrm{~mm})$. Though the rainfall was more, the inundation area did not increase due to the reservoirs built across rivers such as Pamba and Kakki, and a spillway built across the rivers Manimala, Meenachil and Achenkovil, all of which drain into Vembanad lake and then into the Arabian sea. This led to a slight increase in inundation area despite the study area experiencing a couple of heavy rainfall events ${ }^{45}$.

After the rainfall during 15-17 August 2018, the flood event resulted in about 402.2 sq. $\mathrm{km}$ of inundated area. The combined effect of heavy rainfall in both Kottayam and Alappuzha districts and the simultaneous opening of reservoirs (reservoir outflow during the flood event accessed from the Central Water Commission (CWC) report $^{44}$ ) caused higher inflow of water to the Vembanad lake area. Due to the land-use change pattern of the lake, it was reported that its carrying capacity to hold water inflow had reduced from 1.63 to only 0.63 billion cubic metres (BCM) (ref. 44). All these factors contributed to the devastating flood event that occurred from 15 August to 27 August 2018. Figure 7 indicates that the grey bar showing $480 \mathrm{sq}$. $\mathrm{km}$ was the inundated area estimated for Kottayam and Alappuzha after the flood event by the CWC report ${ }^{44}$. This estimate was used as the secondary data validation for the present study. The RGB-based 
inundation mapping algorithm had estimated an area of about $402.22 \mathrm{sq}$. $\mathrm{km}$ on 21 August 2018. The graph also shows a decrease in the inundation area as the inundated region started draining after 21 August 2018 in the RGBbased estimate.

The increasing and receding flood pattern is shown using an RGB composite of the time series. The inputs for the RGB composite for flood occurrence (change map 1) and its recession (change map 2) were the RGBderived inundation maps (Table 6).

The inundation inputs from each period contribute to the difference in colour for both RGB composites. In case of increasing flood pattern shown in change map 1 (Figure 8), the pixels inundated throughout the time series are shown in white colour. The absence of red colour clearly indicates that the region has been flooded after 9 August 2018. Regions which are green in colour are those that were flooded during the event and receded before 27 August 2018. In contrast, the regions in cyan colour have been inundated from the flood event till 27 August with respect to the RGB composite analysis. The pixels representing yellow colour highlight the flooded regions on both 9 and 21 August 2018. Few magenta and blue pixels indicate the region was inundated before and after the flood event, the reason for which is unclear.

The recession in the flood inundated area is shown in change map 2 (Figure 9). The red coloured region indicates areas flooded on 21 August and drained thereafter. White colour shows areas being inundated from 21 August to 2 September 2018. While yellow colour depicts floods during 21 August and 27 August 2018, that had drained thereafter.

The accuracy assessment performed using indices based on ground truth showed considerably high overall accuracy than CSI. The value of CSI that describes flood class alone is promising considering implementing rulebased thresholding for flood mapping. The CSI and $\kappa$ values are almost similar, whereas the difference between CSI and OA is majorly attributed to misclassification that occurred in the non-flood class. The study can be further explored by integrating the satellite-derived flood maps with hydrologic and hydrodynamic modelling.

\section{Conclusion}

With the launch of the Sentinel-1 SAR satellite, the potential utility of freely available SAR data for various applications has increased primarily due to the availability of large time-series SAR data. The mapping of large spatial regions affected by natural disasters such as floods is essential for targeted relief efforts. This study explores the utility of dual-pol SAR data for accurate flood inundated mapping using simple techniques. It demonstrates flood-inundated mapping capabilities for various datasets acquired on single and multi-temporal dates. The study highlights using a rule-based classifier in case of availa- bility of pre-flood images where an RGB image is formed by pre- and post-flood images. It also demonstrates the flood inundation mapping of regions without any pre-flood imagery. The dual-pol single-pass ALOS-2/ PALSAR-2 can provide efficient flood maps. Nonetheless, the freely available Sentinel-1 imagery has the maximum potential utility for inundation area mapping and change detection monitoring due to its reliable 12-day repeat-pass orbit. The results show that a considerable accuracy of $81.6 \%$ (CSI) is achieved with the rule-based classification technique. Simple and concise maps were generated to understand the progression and retreat of the flood event by combining the results obtained from multitemporal images. This approach is scalable and can be applied to any other flood events. This study demonstrates the ability of simple SAR techniques for the generation of reliable flood inundation maps at a relatively high temporal resolution. It can be extended further by developing automatic flood-inundated mapping techniques using Sentinel-1 time series data on cloud computing platforms such as Google Earth Engine.

1. Huang, X. et al., Flood hazard in hunan province of China: an economic loss analysis. Nat. Hazards, 2008, 47, 65-73.

2. Rijal, S., Rimal, B. and Sloan, S., Flood hazard mapping of a rapidly urbanizing city in the foothills (Birendranagar, Surkhet) of Nepal. Land, 2018, 7, 60.

3. Ologunorisa, T. and Abawua, M., Flood risk assessment: a review. J. Appl. Sci. Environ. Manage., 2005, 9, 57-63.

4. Panhalkar, S. and Jarag, A. P., Flood risk assessment of Panchganga River (Kolhapur district, Maharashtra) using GIS-based multicriteria decision technique. Curr. Sci., 2017, 112, 785-793.

5. Cleve, C., Kelly, M., Kearns, F. R. and Moritz, M., Classification of the wildland-urban interface: a comparison of pixel-and objectbased classifications using high-resolution aerial photography. Comput. Environ. Urban Syst., 2008, 32, 317-326.

6. Horritt, M. S., Mason, D. C. and Luckman, A. J., Flood boundary delineation from Synthetic Aperture Radar imagery using a statistical active contour model. Int. J. Remote Sensing, 2001, 22, 2489-2507.

7. Horritt, M., Waterline mapping in flooded vegetation from airborne SAR imagery. Remote Sensing Environ., 2003, 85, 271-281.

8. Zhou, C., Luo, J., Yang, C., Li, B. and Wang, S., Flood monitoring using multi-temporal AVHRR and RADARSAT imagery. Photogrammetric Eng. Remote Sensing, 2000, 66(5), 633-638.

9. Pierdicca, N., Pulvirenti, L., Boni, G., Squicciarino, G. and Chini, M., Mapping flooded vegetation using COSMO-SkyMed: comparison with polarimetric and optical data over rice fields. IEEE J. Selected Top. Appl. Earth Observ. Remote Sensing, 2017, 10, 2650-2662.

10. Hess, L. L., Melack, J. M. and Simonett, D. S., Radar detection of flooding beneath the forest canopy: a review. Int. J. Remote Sensing, 1990, 11, 1313-1325.

11. Hess, L. L., Melack, J. M. and Davis, F. W., Mapping of floodplain inundation with multi-frequency polarimetric SAR: use of a tree-based model. In Proceedings of IGARSS '94 - IEEE International Geoscience and Remote Sensing Symposium, Pasadena, CA, USA, 1994, pp. 1072-1073.

12. Hess, L. L., Melack, J. M., Filoso, S. and Wang, Y., Delineation of inundated area and vegetation along the Amazon floodplain with the SIR-C synthetic aperture radar. IEEE Trans. Geosci. Remote Sensing, 1995, 33, 896-904. 
13. Hess, L. L. and Malack, J. M., Mapping floodplain vegetation in the central Amazon basin with multi-temporal SIR-C data. In IGARSS 98 - Sensing and Managing the Environment. 1998 IEEE International Geoscience and Remote Sensing. Symposium Proceedings (Cat. No.98CH36174), IEEE, Seattle, WA, USA, 1998, vol. 4, p. 2115.

14. Hess, L., Dual-season mapping of wetland inundation and vegetation for the central Amazon basin. Remote Sensing Environ., 2003, 87, 404-428.

15. Arnesen, A. S. et al., Monitoring flood extent in the lower Amazon River floodplain using ALOS/PALSAR ScanSAR images. Remote Sensing Environ., 2013, 130, 51-61.

16. Alahacoon, N., Matheswaran, K., Pani, P. and Amarnath, G., A decadal historical satellite data and rainfall trend analysis (20012016) for flood hazard mapping in Sri Lanka. Remote Sensing, 2018, 10, 448.

17. Martinis, S. and Rieke, C., Backscatter analysis using multitemporal and multi-frequency SAR data in the context of flood mapping at River Saale, Germany. Remote Sensing, 2015, 7, 7732-7752.

18. Pierdicca, N., Chini, M., Pulvirenti, L. and Macina, F., Integrating physical and topographic information into a Fuzzy scheme to map flooded area by SAR. Sensors, 2008, 8, 4151-4164.

19. Pulvirenti, L., Pierdicca, N., Boni, G., Fiorini, M. and Rudari, R., Flood damage assessment through multitemporal COSMOSkyMed data and hydrodynamic models: the Albania 2010 case study. IEEE J. Sel. Top. Appl. Earth Obs. Remote Sensing, 2014, 7, 2848-2855.

20. Pulvirenti, L., Marzano, F. S., Pierdicca, N., Mori, S. and Chini, M., Discrimination of water surfaces, heavy rainfall and wet snow using COSMO-SkyMed observations of severe weather events. IEEE Trans. Geosci. Remote Sensing, 2014, 52, 858-869.

21. Voormansik, K., Praks, J., Antropov, O., Jagomagi, J. and Zalite, $\mathrm{K}$., Flood mapping with TerraSAR-X in forested regions in estonia. IEEE J. Sel. Top. Appl. Earth Observ. Remote Sensing, 2014, 7, 562-577.

22. Cao, H., Zhang, H., Wang, C. and Zhang, B., Operational flood detection using Sentinel-1 SAR data over large areas. Water, 2019, 11, 786.

23. Anusha, N. and Bharathi, B., Flood detection and flood mapping using multi-temporal synthetic aperture radar and optical data. Egypt. J. Remote Sensing Space Sci., 2020, 23, 207-219.

24. Kundu, S., Aggarwal, S., Kingma, N., Mondal, A. and Khare, D., Flood monitoring using microwave remote sensing in a part of Nuna river basin, Odisha, India. Natural Hazards, 2015, 76, 123138 .

25. Baghdadi, N., Bernier, M., Gauthier, R. and Neeson, I., Evaluation of C-band SAR data for wetlands mapping. Int. J. Remote Sensing, 2001, 22, 71-88.

26. Greifeneder, F., Wagner, W., Sabel, D. and Naeimi, V., Suitability of SAR imagery for automatic flood mapping in the Lower Mekong basin. Int. J. Remote Sensing, 2014, 35, 2857-2874.

27. Yulianto, F., Sofan, P., Zubaidah, A., Sukowati, K. A. D., Pasaribu, J. M. and Khomarudin, M. R., Detecting areas affected by flood using multi-temporal ALOS PALSAR remotely sensed data in Karawang, West Java, Indonesia. Nat. Hazards, 2015, 77, 959-985.

28. Chini, M., Hostache, R., Giustarini, L. and Matgen, P., A hierarchical split-based approach for parametric thresholding of SAR images: flood inundation as a test case. IEEE Trans. Geosci. Remote Sensing, 2017, 55, 6975-6988.

29. Giustarini, L., Hostache, R., Matgen, P., Schumann, G. J.-P., Bates, P. D. and Mason, D. C., A change detection approach to flood mapping in urban areas using TerraSAR-X. IEEE Trans. Geosci. Remote Sensing, 2013, 51, 2417-2430.

30. Refice, A. et al., SAR and InSAR for flood monitoring: examples with COSMO-SkyMed data. IEEE J. Sel. Top. Appl. Earth Observ. Remote Sensing, 2014, 7, 2711-2722.
31. Pulvirenti, L., Chini, M., Pierdicca, N. and Boni, G., Use of SAR data for detecting floodwater in urban and agricultural areas: the role of the interferometric coherence. IEEE Trans. Geosci. Remote Sensing, 2016, 54, 1532-1544.

32. Amitrano, D., Di Martino, G., Iodice, A., Riccio, D. and Ruello, G., Unsupervised rapid flood mapping using Sentinel-1 GRD SAR images. IEEE Trans. Geosci. Remote Sensing, 2018, 56, 32903299.

33. Martinis, S., Plank, S. and Ćwik, K., The use of Sentinel-1 timeseries data to improve flood monitoring in arid areas. Remote Sensing, 2018, 10, 583.

34. Jo, M.-J., Osmanoglu, B., Zhang, B. and Wdowinski, S., Flood extent mapping using dual-polarimetric Sentinel-1 synthetic aperture radar imagery. ISPRS - Int. Arch. Photogramm., Remote Sensing Spat. Inf. Sci., 2018, XLII-3, 711-713.

35. Tsyganskaya, V., Martinis, S., Marzahn, P. and Ludwig, R., Detection of temporary flooded vegetation using Sentinel-1 time series data. Remote Sensing, 2018, 10, 1286.

36. Plank, S., Jüssi, M., Martinis, S. and Twele, A., Mapping of flooded vegetation by means of polarimetric Sentinel-1 and ALOS2/PALSAR-2 imagery. Int. J. Remote Sensing, 2017, 38, 3831-3850.

37. Ramsar, Annotated list of wetlands of international importance, 2018; http://saconenvis.nic.in/publication/Ramsar-Sites-annotatedsummary-India.pdf

38. India Meteorological Department, Performance of South West Monsoon 2018 over Kerala. Meteorological Centre, Thiruvananthapuram, 2018, pp. 1-16.

39. Bhatt, C. M., Rao, G. S., Diwakar, P. G. and Dadhwal, V. K., Development of flood inundation extent libraries over a range of potential flood levels: a practical framework for quick flood response. Geomat., Nat. Hazards Risk, 2017, 8(2), 384-401.

40. Chung, H.-W., Liu, C.-C., Cheng, I.-F., Lee, Y.-R. and Shieh, M.-C., Rapid response to a typhoon-induced flood with an SARderived map of inundated areas: case study and validation. Remote Sensing, 2015, 7, 11954-11973.

41. Stephens, E., Schumann, G. and Bates, P., Problems with binary pattern measures for flood model evaluation. Hydrol. Process., 2014, 28, 4928-4937.

42. Chaabani, C., Chini, M., Abdelfattah, R., Hostache, R. and Chokmani, K., Flood mapping in a complex environment using bistatic TanDEM-X/TerraSAR-X InSAR coherence. Remote Sensing, 2018, 10(12), 1873.

43. Feng, Q., Liu, J. and Gong, J., Urban flood mapping based on unmanned aerial vehicle remote sensing and random forest classifier - a case of Yuyao, China. Water, 2015, 7, 1437-1455.

44. Feng, Q., Gong, J., Liu, J. and Li, Y., Flood mapping based on multiple endmember spectral mixture analysis and random forest classifier - the case of Yuyao, China. Remote Sensing, 2015, 7, 12539-12562.

45. CWC, Study Report: Kerala Flood of August 2018. Hydrological Studies Organization, Central Water Commission, Government of India, 2018, pp. 1-46.

ACKNOWLEDGEMENTS. We thank the Japanese Aerospace Exploration Agency (JAXA) for providing ALOS-2/PALSAR-2 data under Project Nos: JAXA-1396; Prof. Harsha Rajan for the photographs captured during the floods in Kerala, and Canalpy, Tata Institute of Social Sciences, Mumbai, for sharing field data. V.S.K.V. also thanks the Ministry of Human Resource Development, Government of India, for providing the necessary computational facilities through a project (14MHRD005) funding.

Received 29 June 2020; revised accepted 26 November 2020

doi: $10.18520 / \mathrm{cs} / \mathrm{v} 120 / \mathrm{i} 5 / 915-925$ 